
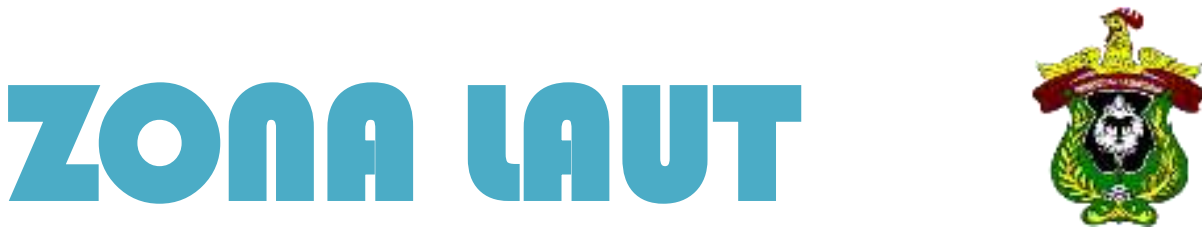

JURNAL INOVASI SAINS DAN TEKNOLOGI KELAUTAN

\title{
ANALISIS KAPASITAS TEKNIS STRUKTUR DERMAGA PELABUHAN LAMPIA
}

\author{
*Chairul Paotonan, Sabaruddin Rahman, Ahmad Azwar Mas’ud M dan Teguh Pairunan Putra \\ Departemen Teknik Kelautan Universitas Hasanuddin \\ *paotonan_ch@yahoo.com
}

\begin{abstract}
Abstrak
PT. Sinergi Perkebunan Nusantara berencana menggunakan pelabuhan Lampia untuk pengapalan Crude Palm Oil (CPO). Dermaga Lampia telah berumur lebih dari sepuluh tahun sehingga daya dukungnya terhadap beban eksternal mungkin telah mengalami menurun.Oleh sebab itu untuk keamanan operasional kapal maka perlu dilakukan kajian terkait kapasitas teknis dermaga tersebut. Dengan diketahuinya kapasitas teknis dermaga maka dimensi kapal maksimum yang dapat dilayani dapat diketahui. Penelitian ini dimulai dari pengumpulan data pendukung yang terdiri dari data kapal, data hidro-oseanografi, data batimetri, data struktur dermaga dan data gempa. Selanjutnya dilakukan perhitungan beban yang bekerja pada dermaga yang terdiri dari beban mati dan beban hidup, beban gempa, beban benturan kapal, beban arus, beban gelombang, beban tarik kapal dan beban angin. Setelah perhitungan beban selesai, selanjutnya dilakukan pemodelan dermaga menggunakan perangkat lunak SAP2000 yang dilanjutkan dengan penginputan beban yang menggunakan kombinasi pembebanan tertentu serta dilakukan running model. Pada penelitian ini dilakukan variasi dimensi kapal yaitu 500 DWT, 700 DWT, 1000 DWT, 2000 DWT dan 3000 DWT. Indikator yang digunakan dalam menilai kapasitas teknis dermaga adalah safety factor (SF) sebagai fungsi dari DWT kapal. Berdasarkan hasil analisis kekuatan struktur dermaga, diperoleh bahwa dermaga eksisting mampu dan aman melayani kapal dengan ukuran $\leq 1027$ DWT jika menggunakan safety factor (SF) 1,5. Sedangkan jika menggunakan safety factor (SF) 2,0 maka struktur dermaga eksisting mampu dan aman melayani kapal dengan ukuran $\leq 510$ DWT.
\end{abstract}

Kata Kunci: Dermaga, Beban dan Faktor Keamanan.

\begin{abstract}
Abstrct
PT. Sinergi Perkebunan Nusantara plans to use the Lampia port for shipping of Crude Palm Oil (CPO). Lampia Jetty has more than ten years old so that its carrying capacity against external loads may have decreased. Therefore for the operational safety of the ship, it is necessary to study the engineering capacity of the pier. By knowing the engineering capacity of the existing pier, the maximum ship dimensions that can be served by pier can be determined. This study began with the collection of supporting data consisting of ship data, hydro-oceanographic data, bathymetry data, pier structure data and earthquake data. Furthermore, the load calculation that works on the pier consists of dead and live loads, earthquake loads, ship impact loads, current loads, wave loads, ship tensile loads and wind loads. After the load calculation is completed, then the pier modeling is done using SAP2000 software followed by inputting the load using a specific combination of loading and running model. In this study the dimensions of the ship were varied namely 500 ton, 700 ton, 1000 ton, 2000 ton and 3000 ton. The indicator used in assessing the technical capacity of the pier is the safety factor $(S F)$ as a function of the ship DWT. Based on the results of the strength analysis of the pier structure, it was found that the existing pier is capable and safe serving ships with a size of 271027 DWT if it uses a safety factor (SF) 1.5. Whereas if use the safety factor $(S F)$ 2.0, the existing pier structure is capable and safe to service ships with a size of $\leq 510 \mathrm{DWT}$.
\end{abstract}

Keywords: Pier, Loads and Safety Fcctor. 


\section{PENDAHULAN}

Pelabuhan Lampia direncanakan untuk digunakan oleh PT. Sinergi Perkebunan Nusantara untuk loading Crude Palm Oil. Sebelum rencana tersebut direalisasikan, perlu dilakukan kajian untuk mengetahui kapasitas teknis struktur dermaga. Oleh sebab itu pada penelitian ini dilakukan kajian kapasitas teknis dermaga untuk mengetahui kondisi struktur dermaga eksisting. Penelitian yang terkait dengan kajian. Kapasitas teknis dermaga dalam menerima beban benturan kapal telah dilakukan beberpa peneliti [1], [2], [3], [4]. Peneliti terdahulu tersebut melakukan analisis struktur dengan menggunakan perangkat lunak untuk dermaga yang belum terbangun. Sedangkan untuk penelitian ini, kajian lebih difokuskan pada dermaga yang telah terbangun. Hal ini perlu dilakukan untuk dermaga pelabuhan Lampia karena pelabuhan tersebut akan dimanfaatkan untuk melayani kapal CPO yang mana karakteristik dan dimensinya berbeda dengan kapal rencana pada saat perencanaan awal. Selain itu, pelabuhan Lampia dibangun tahun 2010 dan akan digunakan pada tahun 2021, kemungkinan daya dukung teknisnya telah menurun. Oleh sebab itu, kajian terkait kapasitas teknis dermaga eksisting mutlak untuk dilakukan untuk menjamin keamanan operasional kapal di dermaga.

\section{METODE}

Pelabuhan Lampia berada di Teluk Bone tepatnya di Kabupaten Luwu Timur Provinsi Sulawesi Selatan. Secara astronomis, pelabuhan lampia berada pada 282223.08 m BT dan 9692911.34 m LS. Data pendukung yang digunakan dalam penelitian ini berupa data hasil survei lapangan berupa dimensi dermaga dan tiang pancang, kondisi batimetri, hidro-oseanografi dan mutu beton dermaga eksisting [5]. Kapal rencana bersumber dari Dokumen Studi Kelayakan Pembangunan Instalasi Tangki Timbun CPO dan Kernel PT. Sinergi Perkebunan Nusantara (2019). Kondisi kegempaan berupa peta zonasi gempa tahun 2011 oleh PUSKIM dan ITB. Penelitian ini dimulai dari Pengumupulan data meliputi data kapal, layout dan dimensi dermaga, struktur dermaga, arus, gelombang dan gempa. Selanjutnya dilakukan perhitungan beban mati dan beban hidup, beban gempa, beban benturan kapal, beban arus, beban gelombang, beban tarik kapal dan beban angin. Selanjutnya dilakukan pemodelan dermaga menggunakan perangkat lunak SAP2000 dan dilanjutkan dengan penginputan beban dan running model. Pada penelitian ini dilakukan variasi bobot kapal yaitu 500 ton, 700 ton, 1000 ton, 2000 ton dan 3000 ton. Indikator yang digunakan dalam menilai kapasitas teknis dermaga adalah safety factor (SF) sebagai fungsi dari DWT kapal.

\section{LANDASAN TEORI}

Gaya yang bekerja pada dermaga dibedakan menjadi dua yaitu beban vertikal dan beban horizontal. Adapun beban vertikal dermaga meliputi beban mati dan beban hidup sedangkan beban horizontal terdiri atas beban benturan kapal, beban angin, beban arus, beban gelombang, beban tarikan kapal dan beban gempa. Beban Mati merupakan berat sendiri dari bangunan yakni beban pelat lantai dermaga yang terbuat dari material beton sendiri dengan $\gamma=2,4 \mathrm{t} / \mathrm{m}^{3}$ [1]. Beban hidup yang bekerja secara vertikal adalah muatan hidup yang terdiri atas muatan merata, muatan terpusat akibat roda-roda truck, mobil, crane, mobil crane, forklift, transtainer dan peralatan yang bekerja di atas latai dermaga. Penentuan beban hidup mengikutki Standard Design Criteria for Ports in Indonesia, 1984. Pada saat kapal merapat ke dermaga dengan sudut merapat adalah $10^{\circ}$, akan terjadi benturan antara kapal dan dermaga dengan energi benturan seperti yang dirumuskan pada Persamaan 1-5 sebagai berikut [6].

$$
\begin{gathered}
E=\frac{W x V^{2}}{2 g} \times C_{m} \times C_{e} \times C_{s} \times C_{c} \\
C_{m}=1+\frac{\pi x d}{2 \times C_{b} \times B} \\
C_{b}=1+\frac{W}{\operatorname{Lpp} \times \gamma_{o} \times B \times d}
\end{gathered}
$$




$$
\begin{gathered}
C_{e}=1+\frac{1}{1+\left(\frac{l}{r}\right)^{2}} \\
F=\frac{W x V^{2} x \sin ^{2} \alpha}{2 x g x d f}
\end{gathered}
$$

Dimana E, W, V, Cm , Ce, Cs, Cc, Cb, d, B, Lpp, $\gamma_{o}, 1, r$, df dan $\alpha$ masing-masing adalah energi benturan kapal dalam satuan ton.m, berat kapal (4/3 DWT) dalam ton, kecepatan kapal saatmembentur dermaga dalam $\mathrm{m} / \mathrm{s}$, koefisien massa, koefesien eksentrisitas, koefisien kekerasan (nilainya $=1$ ), koefisien bentuk dari tambatan (nilainya =1), koefisien blok kapal, draft kapal dalam m, lebar kapal dalam m, panjang kapal dalam $\mathrm{m}$, berat jenis air laut dalam $\mathrm{t} / \mathrm{m}^{3}$, jarak sepanjang permukaan air pada dermaga dari pusat berat kapal sampai titik sandar kapal (dimana untuk dermaga $1=1 / 4$ Loa dan untuk dolphin $1=1 / 6$ Loa) dalam $\mathrm{m}$, jari-jari putaran disekeliling pusat berat kapal pada permukaan air, defleksi fender dan sudut kapal ketika membentur dermaga yang nilainya diambil $10^{\circ}$. Penentuan nilai $l$ dan $r$ disajikan pada Gambar 1a dan Gambar $1 \mathrm{~b}$.



(2.a)

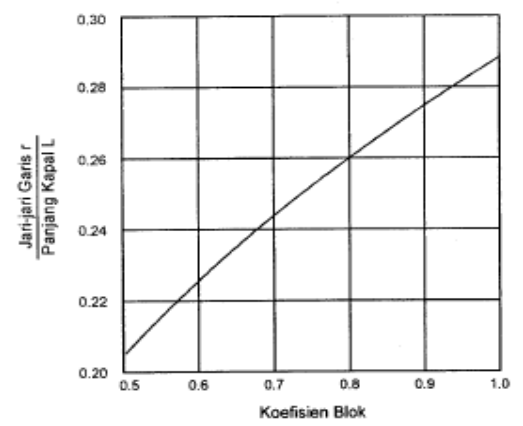

(2.b)

Gambar 1.a. Jarak Pusat Berat Kapal Sampai Titik Sandar Kapal dan

2.b. Jari-jari Disekeliling Pusat Berat Kapal

Angin yang bertiup dan mengenai kapal yang bersandar di dermaga menyebabkan adanya gaya tambahan yang bekerja pada dermaga dan disebut gaya angin. Besar gaya angin tergantung pada arah hembus angin seperti yang diperlihatkan pada Persamaan 6, 7 dan 8 [7].

$$
\begin{gathered}
R w=0,42 \times Q a \times A w, \text { untuk angin dari haluan, } \alpha=0^{\circ} \\
R w=0,50 \times Q a \times A w, \text { untuk angin dari buritan, } \alpha=180^{\circ} \\
R w=1,10 \times \text { Qa } \times A w, \text { untuk angin dari sisi kapal, } \alpha=90^{\circ}
\end{gathered}
$$

Dimana Rw adalah gaya akibat angin dalam $\mathrm{kg}$, Qa adalah tekanan angin $\left(=0,063 \mathrm{~V}^{2}\left(\mathrm{~kg} / \mathrm{m}^{2}\right)\right.$ dalam, V adalahkecepatan angin dalam $\mathrm{m} / \mathrm{s}$, Aw adalah proyeksi bidang yang ditiup angin dalam $\mathrm{m}^{2}$ dan Loa adalah Panjang kapal dalam $\mathrm{m}$. Akibat adanya angin yang bekerja pada kapal akan menyebabkan adanya momen angin Mw yang dirumuskan seperti Persamaan 9 [7].

$$
M w=0,08 \times R w \times L o a,
$$

Pergerakan massa air akibat pasang surut menyebabkan timbulnya arus yang disebut arus pasang surut. Bagian kapal yang terendam dalam air mengalami gaya akibat arus tersebut. Gaya arus yang bekerja pada kapal akan diteruskan ke dermaga baik berupa tekanan. Besar gaya yang ditimbulkan oleh arus diberikan oleh Persamaan 10 dan 11 [8].

$$
\begin{gathered}
\mathrm{Rf}=0,14 \times \mathrm{S} \times \mathrm{V}^{2} \\
\mathrm{Rf}=0,50 \times \rho \times \mathrm{C}^{2} \mathrm{~V}^{2} \times \mathrm{B}
\end{gathered}
$$


Dimana Rf, S, $\rho, C, V$ dan B masing-masing adalah gaya akibat arus dalam kg, adalah luas penampang kapal yang terendam oleh air dalam $\mathrm{m}^{2}$, rapat massa air laut dalam $\mathrm{kg} / \mathrm{m}^{3}$, koefisien tekanan arus (diambil 1) dan kecepatan arus dalam m/s. Besarnya gaya tekan dan tarikan pada boulder yang disebabkan oleh angin dan arus yang terjadi pada kapal. Gaya angin dan arus selain bekerja secara langsung pada dermaga juga bekerja pada alat tambat (boulder) berupa gaya tarik. Resultan gaya tambatan atau gaya tarik pada boulder disebabkan oleh gaya angin dan arus yang bekerja pada kapal yang ditambatkan di dermaga dirumuskan dengan Persamaan 12, 13 dan 14.

$$
\begin{gathered}
P=F D+R w \\
F_{D}=C_{D} \frac{\gamma_{o}}{2 g} A U^{2} \\
T=\frac{P x \sin 30}{\sin 30 x \cos 25}
\end{gathered}
$$

Beban gelombang yang bekerja diasumsikan bahwa bangunan adalah vertikal sehingga pendekatan yang dikembangkan oleh Goda (1985) dapat digunakan untuk menghitung gaya gelombang dengan asumsi distribusi tekanan pada dinding vertikal adalah trapesium seperti yang diperlihatkan pada Gambar 2 [6].



Gambar 2. Dsitribusi tekanan gelombang pada kapal yang bersandar pada dermaga

Pada Gambar 2 diperoleh bahwa d, D, $\mathrm{f}_{\mathrm{b}}, \mathrm{X}_{1}, \mathrm{X}_{2}$ dan $\mathrm{d}_{\mathrm{bw}}$ masing-masing adalah kedalaman air di depan dermaga, sarat kapal, freeboard kapal, jarak antara muka air rerata dengan tinggi jangkauan pengaruh gaya gelombang pada kapal, jarak antara lantai dermaga dengan deck kapal dan kedalam air di depan dermaga sejauh 5 kali tinggi gelombang signifikan $\left(5 . \mathrm{H}_{\mathrm{s}}\right), \mathrm{p}_{1}, \mathrm{p}_{2}, \mathrm{p}_{3}$, dan $\mathrm{p}_{4}$, masing-masing adalah tekanan gelombang pada permukaan air, tekanan gelombang pada dasar laut dan tekanan gelombang pada jarak sejauh sarat kapal dari permukaan ke arah bawah dan tekanan pada jarak sejauh freeboard kapal dari muka air rereta ke arah atas. Sementara $\mathrm{x}_{1}$ adalah jarak elevasi maksimum dimana tekanan gelombang bekerja. Tekanan gelombang di permukaan dan di dasar perairan dirumuskan seperti Persamaan 15 dan 16 [6].

$$
\begin{aligned}
& p_{1}=\frac{1}{2}(1+\cos \beta)\left(\alpha_{1}+\alpha_{2} \cos ^{2} \beta\right) \gamma_{0} H_{\max } \\
& p_{2}=\frac{p_{1}}{\cosh \left(\frac{2 \pi d}{L}\right)}
\end{aligned}
$$

Dengan $\beta, \mathrm{H}_{\max }, \gamma_{\mathrm{o}}$, d dan $\mathrm{L}$, sudut datang gelombang terhadap bangunan, masing-masing adalah tinggi gelombang maksimum, berat jenis air laut, kedalaman air dan panjang gelombang. Nilai $\alpha_{1}$ dan $\alpha_{2}$, dirumuskan seperti berikut.

$$
a_{1}=0.6+\frac{1}{2}\left(\frac{\frac{4 \pi d}{L}}{\sinh \left(\frac{4 \pi d}{L}\right)}\right)^{2}
$$




$$
a_{2}=\min \left\{\frac{d_{b w}-d}{3 d_{b w}}\left(\frac{H_{\max }}{d^{\prime}}\right)^{2}, \frac{2 d}{H_{\max }}\right\}
$$

Pada saat gelombang membentur dinding vertikal, maka pengaruh tekanan gelombang pada dinding tersebut akan sampai pada jarak tertentu dari muka air rata-rata. Menurut Goda (1985) elevasi maksimum tekanan gelombang masih berpegaruh pada arah vertikal dirumuskan seperti pada Persamaan 19 [6].

$$
x_{1}=0.75(1+\cos \beta) H_{\max }
$$

Dengan memperhatikan distribusi tekanan yang bekerja pada kapal, maka gaya total, $\mathrm{F}_{\text {tot }}$ yang bekerja pada kapal dapat dirumuskan seperti berikut.

$$
F_{\text {tot }}=\left(\frac{1}{2} p_{1}(D+F)\right) L_{O A}+\left(\frac{1}{2}\left(p_{3} D+p_{4} F\right)\right) L_{O A}
$$

Pada Persamaan 19, parameter $\mathrm{F}$ dan $\mathrm{L}_{\mathrm{OA}}$, masing-masing adalah freeboad dan panjang kapal. Gaya total tersebut diasumsikan bekerja pada masing masing-masing fender dan diteruskan ke tiang pancang. Beban gempa merupakan pembebanan lateral yang memiliki variasi yang ditinjai dari dua arah yaitu arah sumbu $\mathrm{x}$ $\left(\mathrm{U}_{1}\right)$ dan sumbu y $\left(\mathrm{U}_{2}\right)$ dimana salah satu dari sumbu ini akan memberikan beban gempa 100\% dan 30\%. Pembebanan $100 \%$ bekerja sumbu struktur terlemah. Nilai U1 dan U2 dihitung dengan menggunakan Persamaan 23 dan 24.

$$
\begin{aligned}
& U 1=P G A \times 9.81 \times 100 \% \\
& U 2=U 1 \times 30 \%
\end{aligned}
$$

Untuk nilai PGA diperoleh dari peta percepatan puncak di batuan dasar (Peak Ground Acceleration / PGA), yang bersumber pada Peta Sumber dan Bahaya Gempa Indonesia Tahun 2017. Sesuai dengan RSNI 28332013 ada beberapa peta yang digunakan dan menggunakan kala ulang 50 dan 75 tahun [9].

\section{HASIL DAN PEMBAHASAN}

Berdasarkan Dokumen Studi Kelayakan Instalasi Tangki Timbun CPO dan Kernel PT.SPN, diperoleh bahwa tinggi dan periode gelombang laut dalam masing-masing adalah $0.47 \mathrm{~m}$ dan 3.61 detik. Sedangkan kecepatan arus saat pasang adalah $0.28 \mathrm{~m} / \mathrm{s}$ dan saat surut $0.42 \mathrm{~m} / \mathrm{s}$. Dermaga terdiri dari trestle dengan panjang $42,5 \mathrm{x}$ $6,0 \mathrm{~m}$ dan dua jetty berukuran $10 \times 40 \mathrm{~m}$. Struktur balok, plat dan pile cap dermaga menggunakan beton bertulang sedangkan tiang pancang menggunakan steel pile $\varnothing 508,3 \mathrm{~mm}$. Balok memanjang dan melintang berukuran $35 \times 65 \mathrm{~cm}$, pile cap $1,0 \times 1,0 \times 0,75 \mathrm{~m}$ dengan tebal plat $25 \mathrm{~cm}$. Layout dermaga Pelabuhan Lampia diperlihatkan pada Gambar 3.



Gambar 3. Layout Dermaga Eksisting Pelabuhan Lampia [10].

copyright is published under Lisensi Creative Commons Atribusi 4.0 Internasional. 
Mutu beton dermaga Lampia berasarkan hasil uji Schmidt Hammer adalah K-300-K400. Namun, untuk keamanan diasumsikan terjadi degradasi kekuatan beton menjadi K-275 atau f'c $=23,27$ Mpa dan modulus elastisitas beton $(E)=4700 \sqrt{ } 23,27=22671 \mathrm{Mpa}$ serta berat jenis beton bertulang $=2400 \mathrm{~kg} / \mathrm{m}^{3}$. Tiang pancang menggunakan material baja dan diasumsikan telah mengalami degradasi kekuatan sebesar $20 \%$ karena faktor umur dengan $(\mathrm{fy})=80 \%$ x $442 \mathrm{MPa}=336 \mathrm{MPa}$ dan $(f u)=470 \mathrm{MPa}$ dengan modulus elastisitas $(E)=200000 \mathrm{Mpa}$ dan berat jenis baja $=7850 \mathrm{~kg} / \mathrm{m}^{3}$. Kapal yang akan bersandar adalah kapal tanker dengan bobot maksimum 3000 ton karena keterbatasan panajng dermaga. Dalam analisis, dilakukan variasi DWT kapal yaitu 500 ton, 700 ton, 1000 ton, 2000 ton dan 3000 ton. Kapal 500 ton memiliki panjang, lebar, tinggi dan saratnya adalah $42 \mathrm{~m}, 7 \mathrm{~m}, 4.55 \mathrm{~m}$ dan $3 \mathrm{~m}$, kapal 7500 ton memiliki panjang, lebar, tinggi dan saratnya adalah $50 \mathrm{~m}, 8.5 \mathrm{~m}, 5.25 \mathrm{~m}$ dan $3.7 \mathrm{~m}$, kapal 1000 ton memiliki panjang, lebar, tinggi dan saratnya adalah $61 \mathrm{~m}, 9.8 \mathrm{~m}, 5.55 \mathrm{~m}$ dan $4 \mathrm{~m}$, kapal 2000 ton memiliki panjang, lebar, tinggi dan saratnya adalah $77 \mathrm{~m}, 12.2 \mathrm{~m}, 6.55 \mathrm{~m}$ dan $5 \mathrm{~m}$ dan kapal 3000 ton memiliki panjang, lebar, tinggi dan saratnya adalah $88 \mathrm{~m}, 13.8 \mathrm{~m}, 7.15 \mathrm{~m}$ dan $5.6 \mathrm{~m}$.

Berdasarkan dimensi pelat dan massa jenis beton, diperoleh beban pelat sebesar $0,6 \mathrm{t} / \mathrm{m}^{2}$. Beban hidup terdiri dari beban kendaraan dan air hujan yang disumsikan $3 \mathrm{t} / \mathrm{m}^{2}$ (Standard design Criteria for Ports in Indonesia, 1984). Beban benturan kapal untuk bobot 500 ton, 700 ton, 1000 ton, 2000 ton dan 3000 ton masing-masing adalah 4.10 ton, 5.7 ton, 8.2 ton, 16.4 ton, dan 24.6 ton. Beban angin yang bekerja untuk kapal dengan bobot 500 ton, 700 ton, 1000 ton, 2000 ton dan 3000 ton masing-masing adalah 0.24 ton, 0.32 ton 0.41 ton 0.6 ton dan 0.74 ton. Beban arus untuk kapal 500, 700 ton, 1000 ton, 2000 ton dan 3000 ton masing-masing 0.82 ton , 1.21 ton, 1.57 ton, 2.46 ton dan 3.14 ton. Beban tambatan untuk kapal 500 ton adalah 0.25 ton, untuk kapal 700 ton adalah 0.35 ton, untuk kapal 1000 ton adalah 0.46 ton, untuk kapal 2000 ton adalah 0.70 ton dan untuk kapal 3000 ton adalah 0.88 ton. Beban gelombang pada kapal dengan bobot 500 ton, 700 ton, 1000 ton, 2000 ton dan 2000 ton masing-masing adalah 5.0 ton, 5.4 ton, 5.7 ton, 5.9 ton dan 6.3 ton. Beban gempa ditentukan sesuai dengan peta zonasi gempa tahun 2011 oleh PUSKIM-ITB yang diakses secara online. Pemodelan beban gempa dilakukan dengan metode response spectrum. Adapun Lokasi pengambilan data gempa di Lampia, Malili dengan kondisi tanah keras dan letak geografisLatitude (-2.774962678531147) Longitude (121.04321121853843).

Setelah semua data dianalisis selanjutnya dilakukan analsia struktur yang dimulai dengan melakukan pemodelan struktur secara 3D dalam program analisa struktur SAP 2000 seperti yang terlihat pada Gambar 4.

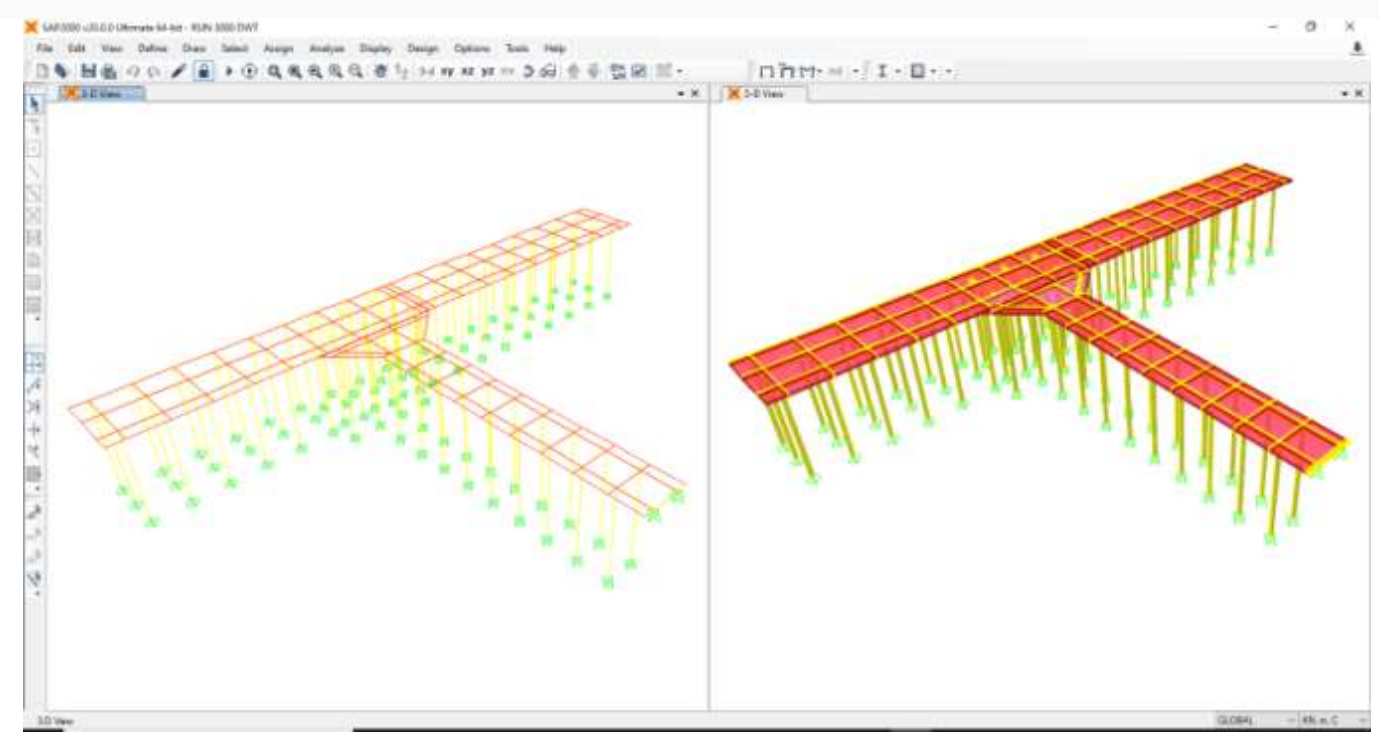

Gambar 4. Model Struktur Dermaga Lampia Pada SAP2000

Setelah struktur dimodelkan selanjutnya beban-beban yang sudah dihitung sebelummya diinput ke dalam SAP 2000. Analisa kapasitas penampang balok dermaga hanya dilakukan terhadap kapasitas dimensi penampang balok saja dan tidak termasuk penulangan aktual eksisting dermaga dikarenakan data penulangan balok dermaga tidak tersedia. Oleh sebab itu, analisa penampang hanya untuk mengetahui kemampuan penampang memikul gaya dan momen geser pada struktur dermaga. Hasil pemodelan balok menunjukkan bahwa kondisi penampang balok pada struktur dermaga tidak terjadi overstress yang diakibatkan oleh gaya 
geser. Artinya balok dermaga masih dalam kondisi aman dari sudut pandang gaya yang bekerja pada struktur untuk semua bobot kapal.

Hasil analisa struktur tiang pancang dermaga menunjukkan bahwa tiang masih mampu memikul beban yang terjadi pada dermaga untuk kapal dengan DWT lebih kecil atau sama dengan 3000 DWT. Rasio maksimum yang terjadi pada tiang pancang untuk kapal dengan DWT 3000 ton sebesar 0,917. Nilai tersebut masih lebih kecil dari rasio tegangan izin sebesar 0,95. Artinya, untuk kapal dengan DWT 3000 ton, tiang pancang masih mampu melayani kapal untuk bersandar. Adapun hubungan antara DWT dengan Safety Factor (SF) dapat dilihat pada Gambar 5.



Gambar 5. Safety Factor (SF) sebagai Fungsi DWT Kapal

Grafik di atas, memperlihatkan bahwa semakin besar bobot kapal, maka SF semakin kecil. Artinya semakin besar bobot kapal, dermaga semakin tidak aman. Gambar 16 memperlihatkan bahwa apabila menggunakan $\mathrm{SF}=1.5$, maka dermaga dinyatakan mampu dan aman melayani kapal hingga DWT $\leq 1027$ ton. Namun, jika menggunakan $\mathrm{SF}=2.0$, maka dermaga dinyatakan mampu dan aman melayani kapal hingga DWT $\leq 510$ ton. Salah satu penyebab berkurangnya kapasitas dukung dermaga dikarenakan adanya degradasi material tiang pancang. Oleh sebab itu, perlu dilakukan tindakan untuk menjaga material tiang pancang pada kondisi layan dengan cara pemasangan cathodic protection sebagai pelindung korosi.

\section{KESIMPULAN}

Data memperlihatkan bahwa struktur dermaga telah mengalami degradasi yang diakibatkan oleh kondisi lingkungan yang agresif. Hasil analisis luaran SAP 2000 memperlihatkan bahwa dermaga eksisting mampu dan aman melayani kapal dengan ukuran $\leq 1027$ DWT jika menggunakan safety factor $(\mathrm{SF})=1,5$. Sedangkan jika menggunakan safety factor $(\mathrm{SF})=2,0$ maka struktur dermaga eksisting mampu dan aman melayani kapal dengan ukuran $\leq 510$ DWT.

\section{DAFTAR PUSTAKA}

[1] Rahmatullah, R., Desain Struktur Dermaga Curah Cair 15000 DWT Pada Pelabuhan Pulang Pisau, Palangkaraya, Kalimantan Tengah Dengan Meninjau Pelaksanaan dan Estimasi Anggaran Biaya dimana merencanakan struktur Dermaga dengan kapasitas 15000 DWT, Institut Teknologi Surabaya (ITS) : Surabaya, 2018.

[2] Nainggolan. L., Analisis Daya Dukung dan Pemodelan Struktur Pondasi Bored Pile Bangunan Penghubung Antar Gedung RSBA Jakarta Timur. Institut Pertanian Bogor (IPB) : Bogor. 2015.

[3] Aditya, R et al., Perencanaan Dermaga Pelabuhan Perinstis Windesi Kab. Kepulauan Yapen, Papua.Jurnal Teknik Sipil, Volume 6, Nomor 1, Tahun 2017, 104-113 Online di : http://ejournalsl.undip.ac.id/index.php/. 2017. 
[4] Zahrah, H., 2018. Perencanaan Struktur Atas Dermaga General Cargo Tipe Pier Berkapasitas 10.000 DWT .Universitas Muhammadiyah Sumatera Utara : Medan

[5] Paotonan, Mas'ud, A.M., Survey Kapasitas Teknis Dermaga Pelabuhan Lampia. Proceedings of Seminar Nasional Sains dan Teknologi Kelautan (2019). 2019.

[6] Triatmodjo, B., Teknik Pantai, Beta Offset :Yogjakarta, 1999.

[7] Triatmodjo, B., Perencanaan Pelabuhan, Beta Offset:Yogjakarta, 2010.

[8] Standard Design Criteria For Ports In Indonesia, Direktorat Jenderal Perhubungan Laut, Departemen Perhubungan, 1984.

[9] Sekolah Pascasarjana Unhas, Studi Kelayakan Pembangunan Instalasi Tangki Timbun CPO dan Kernel PT.Sinergi Perkebunan Nusantara, Universitas Hasanuddin : Makassar, 2019.

[10] Puskim. http://puskim.pu.go.id/Aplikasi/desain_spektra_indonesi2011/, 2020. 